\title{
A randomized control study of preoperative fasting and oral glucose fluid on incidence of perioperative hypoglycemia and hemodynamic
}

\author{
Authors

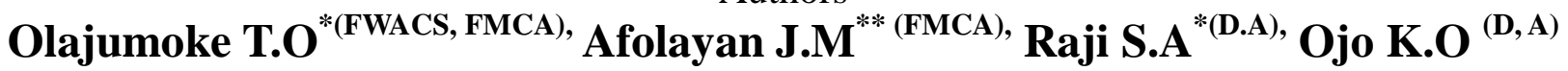 \\ *Department of Anaesthesia and Intensive Care, LAUTECH Teaching Hospital, Oshogbo, Osun State, \\ Nigeria \\ ** Department of Anaesthesia and Intensive Care, Ekiti State Teaching Hospital, Ado-Ekiti, Ekiti State, \\ Nigeria \\ *Corresponding Author \\ Dr Olajumoke T.O \\ Department of Anaesthesia and Intensive Carem, LAUTECH Teaching Hospital, Osogbo, Osun State
}

\begin{abstract}
Aim: This study aimed at finding the effect of preoperative fasting and preoperative glucose oral fluid on perioperative hypoglycemia and haemodynamics.

Methods: Seventy patients of class 1 and 2 ASA status within 2 and 10 years of age were recruited and randomly divided into two groups of thirty five (35) patients each. Group I patients were kept nil per oral from midnight and Group II patients were given clear glucose (2mls per kilogramme) fluid 2 hours prior to the surgery. All surgeries were done under general anaesthesia plus minus endotracheal intubation with standard monitoring. Standard anaesthesia technique was followed for all the patients. Samples were taken for random blood sugar were taken prior to. and immediately after induction of anaesthesia then at 30mins, an hour and 2hours after. The vital signs were taken. baseline before induction and after induction of anaesthesia every 15mins during the surgery and after surgery. The vital signs preoperatively, at induction and at 30mins, an hour and two hours were analyzed.

Result: The average blood glucose was lower in group A $(<50 \mathrm{mg} / \mathrm{dl}$ level of hypoglycemia set for this study) when compared to group B. Group A developed more hypoglycaemia and tachycardia while patients who had fluid intake $2 \mathrm{hrs}$ prior to surgery did not develop hypoglycaemia and have better haemodynamics.

Keywords: children, blood glucose, preoperative, fasting, hypoglycemia.
\end{abstract}

\section{Introduction}

Preoperative fasting is defined as a prescribed period of time before a procedure when patients are not allowed the oral intake of liquids or solids ${ }^{1}$. Hypoglycemia is a perioperative danger in paediatric practice predisposing to lethargy, irritability and metabolic acidosis with resultant anaesthetic problems including seizures. Normally there is a rise in the plasma glucose level in normal adult, but it has been shown that children do not respond with a hyperglycemic reaction to the same degree. The mean normal fasting glucose concentration at birth is $54 \mathrm{mg} / \mathrm{dl}$ with a range of $28-96 \mathrm{mg} / \mathrm{dl}^{[1]}$. The concentration increases in childhood to mean of $77 \mathrm{mg} / \mathrm{dl}$ at 2 years and 92 $\mathrm{mg} / \mathrm{dl}$ at 15 years. After the third day of life, 
hypoglycemia is defined as blood glucose concentration less than $40 \mathrm{mg} / \mathrm{dl}^{2}$.

The relationship between hypoglycemia and hypoglycemic signs has been studied by Gupta et $\mathrm{al}^{3}$. Signs like sweating, headache, excessive crying have been reported to be indicators of hypoglycemia. Apart from hypoglycemia and pulmonary aspiration, other attendant problems associated with the duration of fasting in the perioperative period are risk of metabolic acidosis, hemodynamic instability in the perioperative period, changes in the gastric $\mathrm{pH}$, and speed of recovery from anaesthesia. Robert H.Friesen et al ${ }^{4}$ hypothesized that the duration of perioperative fast affects blood pressure observed in infants during halothane anaesthesia. The study which we conducted, investigated the incidence of hypoglycemia and hypoglycemic signs in the children fasted with two hours preoperative dextrose fluids compared to those without fluids. .

\section{Methods}

This study was carried out at LAUTECH Teaching Hospital Osogbo after ethical approval has been obtained. Children ages between a year and 10 being planned for various elective surgical procedures were recruited for this study after the parents have consented for the study. Patients with any intercurrent illnesses or still breastfeeding were excluded from the study. Seventy patients recruited for the study were randomly categorized into two groups using computer generated tables of random numbers. One of the parents was asked to pick the computer generated numbers in sealed opaque envelops. Group A had 35 patients and the parents were instructed not to give any feeds after midnight to the patients while in group B which also had 35 patients had $2 \mathrm{mls} / \mathrm{kg}$ of dextrose orally 2 hours prior to the surgery. No premedication was given on arrival to the operating room. After checking all equipments. Intravenous line was established with size 22 canulla. While $2 \mathrm{mls}$ of blood was collected from the patients and sent for glucose level estimation immediately. $4.3 \%$ dextrose intravenous fluid was started after baseline vital signs were taken and recorded. Anaesthesia was induced with sodium thiopentone at $5 \mathrm{mg} / \mathrm{kg}$ while patients were intubated with $2 \mathrm{mg} / \mathrm{kg}$ of suxamethonium using appropriate size curved endotracheal tube. Anaethesia was maintained with $0.5 \%$ halothane in $100 \%$ oxygen and $0.1 \mathrm{mg} / \mathrm{kg}$ of pancuronium.

At the end of surgery, the neuromuscular block was reversed with atropine $(0.02 \mathrm{mg} / \mathrm{kg})$ and neostigmine $(0.07 \mathrm{mg} / \mathrm{kg})$ injected intravenously and children were extubated by lying on their sides.

The first blood glucose estimation was performed prior to induction of anaesthesia. After intravenous catheter was inserted, the blood which returned to the hub of needle was drawn for glucose analysis. The second blood glucose estimation was performed immediately after induction of anaesthesia. Blood glucose was thereafter measured at 30mins, an hour; and $2 \mathrm{hrs}$ after induction. Haemodynamic parameters like pulse rate were recorded against the blood glucose levels while incidences of sweating, lethargy, irritability were recorded.

For the purpose of this study hypoglycemia was defined as a blood glucose concentration of less than $50 \mathrm{mg} / \mathrm{dl}$ and hyperglycemia was defined as blood glucose concentration of more than 150 $\mathrm{mg} / \mathrm{dl}$ 4'sss .The study period was two hours; patients were taken to the wards immediately after surgery where monitoring and recording of the parameter continues.

\section{Results}

The average baseline blood glucose was lower in group A compared to group B and it was significant with $p$ value 0.052 though none of patients in either group showed sign of hypoglycemia like lethargy, sweating etc (Table 1) The difference in average blood glucose was not significant in the two groups immediately after induction (Table 2)

The average blood glucose between the two groups was only significant at $30 \mathrm{mins}$ after induction with $\mathrm{p}$ value of 0.05 elsewhere in the 
study period over two hours the difference in blood glucose were not significant (Table 3)

The difference in heart rate was significantly different in the two groups at inception in the theatre from the blood taken during cannulation termed baseline; with $\mathrm{p}$ value 0.052 while the heart rate difference was not significant throughout the study period (Table 4) As earlier stated there was no incidence of any sign of hypoglycemia exhibited by any of the patients even when the blood sugar was lower than the cut off for hypoglycemia

Table 1 Comparison of the baseline blood glucose between groups A and B

\begin{tabular}{|c|c|c|c|}
\hline Group & Baseline blood glucose & p Value & Remark \\
\hline A & $48.42 \pm 11.64$ & 0.052 & \\
\hline B & $88.26 \pm 6.44$ & & S \\
\hline
\end{tabular}

Table 2: Comparison of blood glucose between the two groups immediately after induction of anaesthesia

\begin{tabular}{|l|c|c|c|}
\hline Group & Blood glucose after intubation & $\mathrm{p}$ Value & Remark \\
\hline A & $62 \pm 10.86$ & 0.062 & \multirow{2}{*}{ NS } \\
\hline B & $90.04 \pm 5.24$ & & \\
\hline
\end{tabular}

Table 3: Comparison of blood glucose at 30mins; 1 . \& $2 \mathrm{hrs}$ after induction

\begin{tabular}{|c|c|c|c|}
\hline Groups & BG at $30 \mathrm{mins}$ & BG at an $\mathrm{hr}$ & BG at $2 \mathrm{hrs}$ \\
\hline A & $64 \pm 9.42$ & $66.42 \pm 9.40$ & $72.8 \pm 8.42$ \\
\hline B & $90.0 \pm 5.26$ & $94.62 \pm 5.12$ & $98.64 \pm 4.48$ \\
\hline p Value & 0.050 & 0.062 & 0.072 \\
\hline
\end{tabular}

Table 4: Comparison of heart rates at. Baseline; induction.; at 30mins. an hour \& $2 \mathrm{hrs}$

\begin{tabular}{|l|c|c|c|c|c|}
\hline Groups & HR baseline & HR at induction & HR at 30mns & HR at an hr & HR at 2hrs \\
\hline A & $112 \pm 5.80$ & $130 \pm 5,24$ & $110 \pm 6.20$ & $112 \pm 5.80$ & $108 \pm 6.0$ \\
\hline B & $100 \pm 6.12$ & $116 \pm 5.88$ & $98 \pm 6.46$ & $100 \pm 6.12$ & $96 \pm 6.48$ \\
\hline p Value & 0.062 & 0.064 & 0.0054 & 0.072 & 0.052 \\
\hline
\end{tabular}

S significant; NS not significant

\section{Discussion}

This study was carried out to study the effect of preoperative fasting on hypoglycemia in paediatric patients being planned for surgery and the effect of oral dextrose in reducing the incidence if there is any. The normal fasting regimen most especially in developing countries is nil per oral from $12 \mathrm{mid}$ night as against the 6 hours for solid, 4 hours for liquid diet and breast milk and 2hours for clear fluids. This is also applicable to paediatric patients not minding their different physiology.

This study fasted the patients from midnight while group A were given no fluids; group B patients were given oral dextrose 2 hours before surgery. This study found out that the blood glucose at inception at the theatre was lower and were in the region of hypoglycemia in patients in group B as against those in group $\mathrm{A}$. This is in agreement with previous studies that also found out hypoglycemia in paediatric patients fasted overnight without oral dextrose before surgery. Vikas Sharma ${ }^{4}$ et al in their study comparing the length of fasting and effect of oral dextrose on preoperative hypoglycemia found out there were lower blood glucose in patients not given oral dextrose and was worse in prolonged starvation. Their study is in keeping with our result however the period of fasting was standardized in this study as all cases started at eight o clock on the day of surgery for all cases. Bevan and Burn ${ }^{5}$ and Jenson, Wernberg Anderson ${ }^{6}$ were able to substantiate the incidence of hypoglycemia in paediatric patients that were fasted preoperatively however the duration of starvation before operation did not have any influence on preoperative blood glucose concentrations. Their findings are in keeping with our study however 
fasting period was standardized in our study. J.H. Vander Walt et $\mathrm{al}^{7} \&$ Nancy et $\mathrm{al}^{8}$ in their study on paediatric age group also failed to demonstrate hypoglycemia after preoperative fasting. The difference in the results gotten from their studies may not be unconnected with the difference in the race which might account for the varying response to fasting.

The blood glucose was higher in the two groups after induction as dextrose containing fluids were given however the blood glucose were lower in group A when compared to B throughout the study period with only significance at $30 \mathrm{mins}$ after induction.

The heart rate was higher in group A at inception at the theatre and throughout the study period in group A compared to B suggesting to be sign of hypoglycemia however no other sign was found in either groups in support of hypoglycemia. Diaz et $\mathrm{al}^{9}$ in their. Study found out that the incidence of tachycardia and hypotension was more frequent in infants who fasted for longer than 8 hours before surgery without oral dextrose which is in agreement with our study however we did not measure blood pressure in this study as there was no appropriate paediatric cuff as at the time of this study.

\section{Conclusion}

The result of our study points out that prolonged fasting in the paediatric age group can lead to hypoglycemia; tachycardia as compared to children who have had oral feed of clear fluid that is $5 \%$ Dextrose $2 \mathrm{hrs}$ before induction of anaesthesia

\section{Recommendation}

Based on the result and conclusion of this study; we recommend that paediatric patient being planned for surgery should be fasted with the guideline of 6hours for solid food, 4 hours for liquid foods and breast milk while the two hours of clear fluids preferably about $2 \mathrm{mls} / \mathrm{kg}$ of $5 \%$ dextrose should be enforced to avoid perioperative hypoglycemia and its complications.

\section{References}

1. American Society of Anesthesiologists: Practice guidelines for preoperative fasting and the use of pharmacologic agents to reduce the risk of pulmonary aspiration: Application to healthy patients undergoing elective procedures-a report by the American Society of Anesthesiologists Task Force on Preoperative Fasting. ANESTHESIOLOGY 1999; 90:896-905.

2. Bowie MD, Mulligan PB, Schwartz R. Intravenous glucose tolerance in the normal newborn infant the effects of a double dose of glucose and insulin. Pediatrics. 1963 Apr;31:590-5

3. Pramod Gupta; Sehgal R, Journal of Anaesthesiology Clinical Pharmacology, 2004, 20(2), 161-163

4. Robert H. Friesen, Anaesthesia and Analgesia, 2002, 95, 1572-1576.

5. Bevan JC; Mary C. Burn, British Journal of Anaesthesia, 1973, 45:115s

6. Jensen BH; Wernberg M, British Journal of Anaesthesia, 1982, 54:1071

7. Vander Walt JH and Carter JA, Anaesthesia and Intensive care, 1986, 14,352-359.

8. Nancy Redfern; Addison GM, Anaesthesia, 1986, 41,272-275.

9. Diaz JH, Journal of Paediatric surgery, 1985, 20,502-507. 